survey of DIY biologists released on 19 November by the Woodrow Wilson International Center for Scholars in Washington DC reveals, unsurprisingly, that neither caricature is accurate, and that the DIYbio movement is more nuanced than it would seem to those looking in from the outside (see go.nature.com/nj9xk6).

The movement is made up of enthusiasts with a range of backgrounds and interests in biology, who work in wet-lab spaces not affiliated with traditional science centres such as universities. The survey found that $92 \%$ of DIY biologists work at least some of the time in communal spaces rather than in their garages or basements; that they are mostly young ( $36 \%$ under $35,78 \%$ under 45 ); that they are more educated than the general population; and that many are still learning the basics of biotechnology. Only 6\% of people surveyed said their experiments were of the kind that would require the safety conditions for work that might cause human disease.

It is interesting to note that $28 \%$ of people who responded to the survey said that they already do some or all of their work in academic, corporate or government labs, and that $19 \%$ have obtained a doctorate-level degree. So at least some DIY biologists are peers of - or indeed themselves - readers of this journal, and are within the mainstream scientific community.

This undercuts the notion that all DIY biologists are inexperienced if enthusiastic amateurs. And the report argues that this expertise and access to sophisticated lab facilities mean that the DIY community has the potential to generate products that will benefit society. As a result, it recommends that the US government should fund networks of community lab spaces.

Examples of the positive impact DIYbio can have already exist: its practitioners have produced a cheap alternative to commercial machines for the polymerase chain reaction, and they have come up with an inexpensive diagnostics device for malaria. Yet so far, the projects that have garnered the most attention have been essentially

frivolous, such as the project to create a glowing plant, which collected US $\$ 500,000$ in public crowdsourced funds last year - ten times as much as the malaria tool earned in seed funding.

This highlights the key problem. There is no government granting agency judging which DIY project is worthwhile, so DIY biologists can do what they like, as long as it's legal. Although this is an intrinsic

"DIY biologists can do what they like, as long as it's legal." to and potentially more control over the work that goes on in labs that they fund.

But the report also notes that most DIY biologists do not favour government regulation, now or in the future. Governments, of course, cannot become more involved in supporting this movement without taking a more proactive role towards regulation. Is this apparent impasse permanent? Perhaps not. The report notes that a sizeable minority - $43 \%$ - of DIY biologists do favour some kind of regulation in the future, and this may grow as the movement matures.

The report's authors anticipate such a change. They suggest benchmarks and timelines to address regulation - a time in the future, for instance, when people outside companies and sophisticated labs will be able to synthesize long stretches of DNA. Still, rather than risk being overrun by events, the DIY-biology community and regulators should start to talk about how to anticipate such developments, rather than merely respond to them.

The security and stability of government funds would safeguard the future of the DIYbio movement; the issue is whether the movement would accept the trade-offs that such stability would bring. If you are reading, then do please tell.

\section{Enemy of the good} Universities need to counter pressures that
undermine support for younger researchers.

W ho are the outstanding mentors of young researchers? Since 2005, Nature has awarded an annual prize for scientific mentoring, rotating through a variety of countries. Over the years it has become clear that, regardless of the country and scientific discipline, there are some consistent key characteristics of lab heads that bode particularly well for young scientists under their leadership. Outstanding mentors tend to have a thorough command of their research field. They are highly accessible to the members of their lab. They can relate to individuals in a way that is specific to each person's characteristics. And they know how to balance support with the nurturing of independent creativity, problem-solving, integrity and initiative (see Nature 447, 791-797; 2007).

This year's winners are no exception. The competition was held in Italy, and the awards went to neurobiologist Michela Matteoli, theoretical physicist Giorgio Parisi and chemist Vincenzo Balzani (see pages 443 and 559). All received glowing testimonials from their past trainees. For example, the success of one mentor was ascribed to "complete emotional and scientific investment" in mentees, who in turn "dedicate themselves to work at their best to pay back that faith".

That degree of mentoring commitment is unusual. All too often one meets young researchers who, despite working in prestigious institutions, have had no such experience. Yes, the 'sink or swim' approach can breed resilience, but proper mentoring can safeguard scientific integrity in the full sense of the word. It enables young researchers to develop a critical approach to their own ideas and data, and to maintain professionalism by using robust techniques and analyses. Mentoring also helps to engender a culture of transparency in allowing others access to raw data, gives a sense that one's leader has one's interests at heart, and can moderate the pressure to publish. Universities have a duty to ensure that this culture prevails, not least to ensure that public and private money is not squandered on sloppy, amateurish research.

But especially now, the pressures on young lab leaders are huge. Encounters with early-career principal investigators all too often indicate how narrow their focus must be to survive. They might be adding to those pressures because of hyper-competitiveness or anticipated demands from university and funding-agency committees. Typically, principal investigators are well-intentioned towards their younger colleagues, but feel an obligation to produce strong results in the first few years of their labs, to get funding or tenure. They may often feel that they do not have enough time to invest in mentoring their teams. Or they may well judge that they simply cannot tolerate people in their labs who are underperforming.

Such a lack of attention to nurturing individuals could exacerbate another damaging trend. With more people seeking alternative careers during their PhDs because of the ever tougher prospects in academia, those graduate students might lose motivation to go the extra mile to fulfil their research potential. And yet the principal investigator needs the papers generated by the students' work to get tenure.

These problems can be addressed in two ways: from the bottom up, by a sheer determination of younger lab heads to be responsible leaders; and more importantly, from the top down, by heads of uni- $\rightarrow$ NATURE.COM To comment online, click on Editorials at: go.nature.com/xhunqv versities and departments providing incentives for great leadership. Such heads should look at the winners of the Nature mentoring awards and ask: 'Does my institution cultivate such behaviour or hinder it?' - 